\title{
ATIVIDADE LENTA NAS AREAS POSTERIORES E PROBLEMAS DE COMPORTAMENTO EM CRIANÇAS
}

\author{
Almir Almeida Guimarães *
}

Os estudos eletrencefalográficos em crianças com distúrbios do comportamento vêm despertando interêsse cada vez maior. A grande variedade dos traçados anormais encontrados nesses pacientes merece cuidadosa valorização e meticulosa correlação clínico-eletrencefalográfica, devendo ser desde logo afastada a noção simplista e errada de que eletrencefalograma anormal é igual a epilepsia. Em muitos casos não é fácil estabelecer exata correlação eletroclínica; vislumbra-se, entretanto, uma perspectiva evolutiva onde o interêsse crescente da eletrencefalografia é indiscutível.

Como mostram numerosos trabalhos sôbre o assunto e dada sua complexa intrincação, é sempre necessário um estudo orientado sob os ângulos somático, psicomotor, intelectual, afetivo e bioelétrico, pois certas alterações sugerem a existência de um desenvolvimento defeituoso das estruturas cerebrais. Por outro lado, certas alterações elétricas são observadas em pacientes com distúrbios da linguagem e componente afetivo importante; em geral se trata de focos transitórios que podem representar imaturidade local com heterocronismo de evolução das diferentes áreas. Laget e Salbreux ${ }^{7}$ admitem que as descargas paroxísticas no traçado de certas crianças com distúrbios da psicomotilidade, quando localizadas, devem ser consideradas como focos epileptógenos (Delage) e, na sua apresentação difusa, devem ser interpretadas como indícios de "dismaturação". A discussão ainda está aberta e, em cada caso particular, a evolução regressiva dêsses elementos paroxísticos permite, senão decidir o problema da significação nosológica, pelo menos aliviar a ameaça que êles poderiam representar para numerosos pacientes. Denis Hill, citado por Lairy $^{8}$, considera, no plano psicopatológico, tôda uma série de fenômenos eletrencefalográficos anormais como dependentes de perturbação homeostática do organismo, ligada a desordens tanto funcionais como orgânicas. Assim, torna-se necessário aceitar a realidade das alterações eletro-funcionais temporárias sem despresar, de outro lado, o caráter regressivo das epilepsias da infância.

A evolução do traçado no tempo, quaisquer que sejam as alterações observadas, é o elemento fundamental, pois permitirá formar-se progressivamente uma idéia da capacidade adaptativa de cada indivíduo em função do seu

Co-relatório apresentado ao II Congresso Brasileiro de Electrencefalografia e Neurofisjología Clínica (Pôrto Alegre, julho de 1970): * Membro da Academia Brasileira de Neurologia e da Sociedade Brasileira de Electrencefalografia e Neurofisio. logia Clínica. 
próprio desenvolvimento e da influência do meio ambiente. Na pesquisa do paralelismo evolutivo entre os sinais clínicos e eletrencefalográficos, o EEG esclarece o caráter transitório ou irreversivel das perturbações assim como sua significação, sendo o prognóstico tanto melhor quanto mais o EEG se mostrar susceptivel de evoluir favoràvelmente.

Tentaremos fazer uma apreciação sôbre alguns aspectos dos achados eletrencefalográficos em crianças com distúrbios do comportamento, compreendendo entre elas aquelas rotuladas como hiperativas ou hipercinéticas, nas quais a inquietação motora ou excesso de movimentação são sintomas dominantes, sem déficit intelectual ou distúrbio neurológico apreciável. $\mathrm{O}$ pobre rendimento escolar, freqüentemente referido, decorreria não de baixo nivel intelectual mas de labilidade atentiva e grande dispersividade.

Schulman e col. chegaram a estabelecer o nivel de atividade média ótima diária dentro de um conceito empírico, admitindo que cada paciente tem o seu próprio "regulador" de atividade o qual, nos hipercinéticos, está situado em nível muito alto. Esta avaliação não é obtida mediante aferição direta, mas decorre de informações fornecidas por pessoas que lidam com a criança e observam a sua atividade diária.

Bakwin e Bakwin (1966) adotaram a expressão hiperatividade congênita, definida como aquela observada desde os primeiros anos de vida e que ocorre sem que haja transtôrno importante do sistema nervoso central nem psicose, diferenciando-se da intranquilidade e dos estados de ansiedade ou perturbações reativas da conduta, pelo caráter crônico e falta de início definido. Seria, pois, o nivel de atividade diária que excede de modo evidente o observado nas crianças semelhantes quanto ao sexo, idade, condições econômicosociais e culturais, sem dados manifestos de transtôrno do sistema nervoso central, nem de psicose que venha sendo observada de maneira constante desde os primeiros anos de vida. Nos pré-escolares os sintomas consistem em atividade incessante, o que expõe a criança a perigo, freqüentemente determinando destrutividade; as crianças parecem movidas por energia inesgotável e necessitam menor número de horas de sono do que as normais da mesma idade. Nos escolares as queixas dos mestres dizem respeito à incapacidade da criança em permanecer sentada, movendo-se, andando e falando incessantemente, perturbando, pelo seu comportamento, o funcionamento da classe. Neste grupo dos hipercinéticos encontram-se defeitos de atenção e da excitabilidade, dificuldade de aprendizado, transtornos neurológicos (funcionais) e sintomas emocionais. Da dificuldade de concentrar-se em uma atividade decorre falta de reflexão antes de atuar e conseqüente ação impulsiva. Desencadeiam-se muitas vêzes reações de cólera ou grande excitação provocadas por pequenos estímulos ou decorrentes de frustrações. Do ponto de vista neurológico ocorre uma série de sintomas tais como má coordenação motora, brusquidão de movimentos, ticos, apraxias benignas ligadas a disritmias lentas difusas e assimétricas, embora nenhuma dessas anormalidades possa ser considerada como inequívoca indicadora de lesão importante do sistema nervoso central. Ainda segundo Bakwin, êsses pacientes são levados à consulta por problemas emocionais e de comportamento: em geral são desafiantes 
agressivos, provocadores malquistos entre us colegas e, ainda, dados a mentiras e furtos. Pode haver hiperatividade sem outro transtôrno emocional ou de conduta e, de outro lado, sem problemas de aprendizado ou problemas neurológicos.

Laufer e Denhoff (1957) explicaram a ligação mais freqüente da hiperatividade com outros sintomas emocionais e de comportamento como reação às dificuldades que criam, nas crianças hipercinéticas, os transtornos da atividade e do aprendizado.

Por outro lado, Posamanick e col. (1956) e Clements (1966) opinam que a hiperatividade provàvelmente depende de grau benigno de lesão ou disfunção cerebral (disfunção cerebral mínima). Como é freqüente a associação de hiperatividade, transtornos neurológicos, anormalidades eletrencefalográficas, distúrbios de linguaģem, de comportamento e de percepção, pode-se pensar em etiologia orgânica, embora isso ainda não tenha sido comprovado.

Kellaway, Crowby e Maulsby estudaram mais de 1.000 crianças que revelaram deficiência na escola, constituindo casos rotulados como desordens de comunicação ou de integração perceptiva e de falso retardo mental. Aproximadamente $40 \%$ dessas crianças apresentaram alterações significativas no EEG e as seguintes características clínicas: pobre performance escolar em desacôrdo com o nivel intelectual, nível de desempenho pessoal irregular podendo variar diversas vêzes no mesmo dia, atenção difícil de fixar com marcada distraibilidade; em complementação tais crianças exibem um agudo distúrbio na comunicação, envolvendo leitura, escrita e identificação numérica, que pode ser considerado com uma desordem geral da integração sensóriomotora. Esses autores acreditam que uma avaliação combinada clínica, eletrencefalográfica e psicológica de pacientes dêsse tipo poderá ser muito esclarecedora, permitindo inđicação terapêutica racional. Admitem que vários tipos de disfunção cerebral podem originar a "poor school performance" e que um programa de estudo detalhado clínico, eletrencefalográfico e psicológico deverá ser empreendido. Do ponto de vista eletrencefalográfico alinham as seguintes como as anormalidades mais freqüentes: 1) ondas lentas occipitais ou occípito-temporais e ondas "sharp" isoladas (disritmia lenta occipital); 2) pontas positivas de 6 e $14 \mathrm{c} / \mathrm{s}$ só ou associadas com disritmia lenta occipital; 3) focos de pontas, particularmente nas regiōes temporal e occipital. E importante ressaltar que tais anormalidades podem constituir as únicas evidências objetivas de disfunção cerebral.

Kellaway e col. chamam a atenção para o fato de que $40 \%$ das crianças com foco occipital não apresentam convulsões. Em cêrca de $50 \%$ dêsses casos a etiologia não pode ser determinada ou suspeitada. A ausência de referências a traumatismos cerebrais ou de anormalidades neurológicas não afasta a possibilidade da existência de disfunção cerebral orgânica. Por outro lado, a ocorrência de anormalidades eletrencefalográficas aumenta se há evidência de distúrbio neurológico mínimo ou história de traumatismo cerebral, de infecção ou de outra condição mórbida anterior ou simultânea. 
Os mesmos autores, observando que as anormalidades eletrencefalográficas acima descritas estão associadas, em alguns pacientes, a manifestações convulsivas, empiricamente instituem tratamento anti-convulsivante em muitas delas, pois acreditam que o baixo desempenho escolar poderá resultar de duas condiçōes, juntas ou separadamente: a primeira é a presença de uma lesão cerebral com alterações do tecido nervoso e conseqüente déficit funcional do sistema especìficamente envolvido nos processos de aprendizado, comunicação ou integração sensório-motora; a segunda é a conseqüência de uma descarga irritativa originada em uma lesão cerebral, interferindo esta descarga com a função dos elementos neuronais subjacentes ou distantes, perturbando ou impedindo sua participação normal nas funções integrativas sensório-motoras.

Berges e col. ${ }^{4}$, estudando um grupo de 50 crianças de 6 a 13 anos que apresentavam distúrbios de linguagem e perturbações psicomotoras destacaram vários fatos, como sejam, a relação entre as perturbações do tono muscular (desarmonia tônica) e os traçados mal organizados, a má organização espacial ligada a um rebaixamento do nivel motor global em relação ao nível mental (debilidade motora verdadeira). Ao contrário, os pacientes apresentando perturbação isolada de uma função psicomotora elaborada (dislexia, dificuldade perceptivo-motora sem debilidade motora de fundo), têm, ordinàriamente, EEG bem organizado no plano de discriminação espacial de seus ritmos. Perturbações maciças da organização espacial do EEG acompanham, na criança inteligente sem lesão orgânica, dificuldades particulares importantes dessas aquisições por perturbações motoras instrumentais e de contrôle tônico-motor. A existência de figuras eletrencefalográficas ponteagudas, quer difusas, quer localizadas é, atualmente, reconhecida como fora do domínio da epilepsia. Dos pacientes com distúrbios psicomotores ou dificuldades escolares estudados por Berger e col. ${ }^{4}$, quase $50 \%$ apresentaram tais imagens eletrográficas.

A localização eventual de imagens ponteagudas em indivíduos sem lesões orgânicas nem manifestações comiciais, sugere uma série de problemas teóricos ainda não resolvidos. As localizações posteriores, occipitais ou têmporo-paríeto-occipitais são banais na criança, muitas vêzes reversiveis.

Aird e Gastaut (1959) tentaram precisar a diversidade de aspecto eletrencefalográfico e tirar conclusões clínicas em função dessas características morfológicas. Para êstes autores as imagens de ondas lentas ponteagudas posteriores, quer representem, ou não, componentes harmônicos de ritmo alfa, são encontráveis em indivíduos que apresentam dificuldades específicas, gnósicas ou práxicas, implicando em queda no apuro das tarefas, tais como leitura, reprodução de formas geométricas, ou escrita. Isto confirma as observações de Takerka e Katz (1955) de que as anormalidades posteriores occipitais são observadas principalmente em crianças que apresentam distúrbios da organização perceptivo-motora, não sendo êsses focos elétricos posteriores considerados como anomalias, mas sim como a expressão, em nivel eletrográfico, de um distúrbio ligado a uma dificuldade ou desarmonia maturativa, o mais das vêzes temporária, de determinadas funções. 
Uma exceção pode ser feita para duplo foco elétrico assincrônico que parece corresponder a quadros clínicos tanto mais sérios quando mais idade tenha a criança; o fato do arrastamento fótico não conseguir a resincronização dos ritmos occipitais constitui, igualmente, um elemento indicador de gravidade.

Berges, Harrison e Lairy $^{3}$ estudaram o problema da assincronia dos ritmos posteriores em crianças de idade escolar não encefalopatas, dividindo o material em três grupos: no primeiro, compreendendo 160 casos, incluiram crianças levadas à consulta por dificuldades escolares ou afetivas (5 a 16 anos); no segundo, abrangendo 74 casos, foram agrupadas crianças apresentando problemas oculares, como sejam deficiências visuais graves, ambliopias unilaterais ou estrabismos simples ( 6 a 14 anos); no terceiro grupo, foram estudadas 300 crianças normais para contrôle. Nos comentários finais os autores ressaltam que a assincronia dos ritmos posteriores aparece como um sinal eletrencefalográfico em correlação nítida com um tipo particular de organização das funções simbólicas no curso da maturação da criança. Trata-se, pois, de uma anormalidade eletrográfica de grande utilidade para orientar as investigações clínicas e psicológicas em numerosos casos nos quais o EEG é pedido em função de perturbações de comportamento ou por inadaptação escolar. A ausência de relação linear entre assincronia e idade e entre assincronia e nível mental global mostra que a assincronia dos ritmos posteriores não pode ser considerada como indicadora de simples retardo da maturação neurônica, mas sim como uma desarmonia da maturação eletrencefalográfica. Em quase metade dos casos de assincronia marcada foram destacados dados anamésticos importantes (prematuridade, anóxia neonatal, toxicose). Isso põe em discussão o problema da natureza orgânica ou funcional do quadro eletro-clínico. Um problema a estudar seria a evolução das disarmonias, importando verificar se a sua reversibilidade eventual por reeducação se acompanha de desaparecimento da assincronia. Para os autores citađos as relações entre patologia da visão, dismaturação das funções simbólicas e assincronia dos ritmos ao nível das regiōes de projeção sensoriais visuais ou de integração psico-visuais, merecem ser estudadas de maneira extensiva.

Nayrac e Beaussart estudaram 5 pacientes, antigos traumatizados de crânio (10 meses a 3 anos após o traumatismo), nos quais foi observado um ritmo lento posterior entre $3 \frac{1 / 2}{\text { e }} 4 \frac{1}{2} \mathrm{c} / \mathrm{s}$, sincrônico. Os sintomas comuns a todos os casos eram aqueles da síndrome subjetiva clássica. Admitem êstes autores que tal ritmo provenha de região mesencéfalo-diencefálica e que seja provàvelmente mais a expressão de uma disfunção do que de uma lesão orgânica.

Nas crianças a associação psicológica essencial coincidente com o achado de ondas lentas posteriores é constituida por distūrbios afetivos, embora na nossa experiência tal ritmo seja também encontrado com freqüência em pacientes apresentando crises convulsivas, febris ou não.

Lairy ${ }^{9}$ afirma que a presença de ondas lentas posteriores não deve ser encarada como uma anomalia, nem sinal de mau prognóstico na criança com 
problemas neuro-psiquiátricos. Pelo contrário, constitui indício de prognóstico favorável, visto que bons resultados decorrentes de tratamentos bem indicados - reeducação ou psicoterapia - são mais fàcilmente obtidos em crianças apresentando ondas lentas posteriores do que naquelas que, apresentando o mesmo quadro clínico, tenham EEG normal.

Em certos casos as ondas lentas posteriores, especialmente quando de morfologia ponteaguda, predominam num lado ou são unilaterais, constituindo um foco. Isto é raramente observado nos grupos de crianças normais, ao contrário do que ocorre naquelas com problemas neuro-psiquiátricos, nas quais sua ocorrência é freqüente. As correlações clínicas e psicológicas dêstes focos dependem do lado de sua localização. São habitualmente observados no lado direito em casos em que são assinaladas dificuldades na leitura e escrita, muitas vêzes associadas com atrazo de linguagem; os testes psicométricos revelam distúrbios gnósicos com atrazo de organização da imagem corporal e da noção de espaço. Quando situados no lado esquerdo são comumente associados a distúrbios da escrita e desenho; as investigações psicométricas revelam alterações práxicas e vísuo-motoras.

Aird e Yamamoto ${ }^{1}$ citam, como dificuldades que envolvem o estudo dos distúrbios do comportamento em crianças: 1) o fato da síndrome clínica variar consideràvelmente nas suas manifestações sem delimitação nosológica nítida; 2) o fato dêstes distúrbios se alterarem e muitas vêzes desaparecerem com a idade; 3 ) o fato de ser difícil relacioná-las à determinada patologia ou anomalia; 4) o fato de que estudos correlativos têm mostrado anormalidades em cêrca da metade dos casos e que, em muitos trabalhos, as anormalidades consistem em alterações generalizadas do EEG, dificultando estabelecer correlações significativas. Dos 100 casos estudados por Aird e Yamamoto (crianças de 1 a 16 anos), 51\% mostraram traçados normais, dos quais quatro foram classificados com "bordeline", o que leva à discussão de uma forma primária de desordens da conduta na criança. Entre os traçados anormais foram assinaladas alterações difusas sem elementos focais, anormalidades focais puras ou associadas a anormalidades generalizadas. A localização do foco predominou no lobo temporal, sem dominância de lado, seguindo-se a localização occipital e, depois, em outras regiōes. Os autores constataram alta incidência de dificuldade na leitura no grupo apresentando foco occipital e possivelmente temporal. Os resultados foram apresentados na convicção de que possam proporcionar uma confirmação mais precisa sôbre a suspeitada correlação entre disfunção do lobo temporal indicado pelo EEG e desordens do comportamento da criança.

Assim, os casos clínicos enquadráveis como distúrbios do comportamento englobam condições mórbidas diversas, ressentindo-se de uma delimitação precisa. Não existe um padrão de EEG específico para cada um dos sintomas e sindromes apresentados pelos pacientes com tais distúrbios. Entretanto, se o EEG nem sempre tem valor diagnóstico preciso, constitui valioso dado complementar para investigações psicológicas e orientação terapêutica adequada. Como a condição mórbida aqui considerada altera-se, muitas vêzes, atenua-se ou desaparece com a idade, os eletrencefalogramas sucessivos, com as suas 
modificações, poderão proporcionar elementos interessantes dentro de uma perspectiva evolutiva.

Nos critérios de interpretação do EEG da criança devem ser considerados elementos diversos daqueles do adulto. Segundo Lairy ${ }^{9}$, o EEG da criança com características da do adulto, com leve ou ausente plasticidade, constituindo o EEG "hipernormal", poderá orientar para prognóstico desfavorável, especialmente quando associado com grave estado clínico (deficiência intelectual, neurose ou psicose).

Embora afirme Lairy ${ }^{9}$ que as ondas lentas posteriores bilaterais estão relacionadas com a inteligência, sendo sobretudo observadas em crianças inteligentes e excepcionalmente em deficientes mentais, não temos, na nossa experiência, dados para confirmar tal assertiva. As ondas lentas posteriores nas crianças estão associadas freqüentemente a distúrbios afetivos. No nosso serviço, embora sem referir dados numéricos e estatísticos, há grande proporção de EEG anormais em crianças com distúrbios de comportamento. Encontramos: traçados anormais por excesso de ondas lentas, generalizadas, com predominância posterior, mais comumente à direita; traçados lentos difusos, revelando ainda foco de pontas ou ondas "sharp" em áreas temporais uni ou bilaterais, com maior freqüência à esquerda e nas áreas occipitais; traçados com ritmo lento posterior, constituindo-se muitas vêzes em surtos, sincrônicos ou não ou, ainda, unilaterais; traçados lentos difusos, destacando-se surtos nas áreas temporais (teta) uni e bilaterais, com predominância em um dos lados, habitualmente à esquerda e, muitas vêzes, presentes nos casos apresentando problemas de linguagem.

R E F E R E C I A S

1. AIRD, R. B. \& YAMAMOTO, T. - Behavior disorders of childhood. EEG Clin. Neurophysiol. 21:148, 1966.

2. AIRD, R. B. \& ADAMS, J, E. - The localysing value and significance of minor differences of homologous tracings as shown by serial electroencephalographic studies. EEG Clin. Neurophysiol. 4:45, 1952.

3. BERGES, J.; HARRISON, A. \& LAIRY, G. C. - L'assynchronie des rythmes posferieurs chez l'enfant d'age scolaire non encephalopathes. Rev. Neurol. (Paris) 115:162, 1966.

4. BERGES, J.; NETCHINE, S. \& LAIRY, G. C. - Quelques aspects particuliers du tracé EEG chez l'enfant presentant des troubles de la psychomotricité. Rev. Neurol. (Paris) 109:238, 1963.

5. KELlaWAY, P. \& PETERSEN, J. - Clinical Electroencepholography of Children. Grune \& Straton, New York, 1968.

6. LAGET, P. \& SALBREUX, R. - Atlas d'Electroencephalographie Infantile. Masson et Cie., Paris, 1967.

7. LAIRY, G. C. - Organisation de l'electroencephalogramme normal et pathologique: aspects cliniques. Rev. Neurol. (Paris) 94:749, 1956.

8. LAIRY, G. C. - Quelques remarques sur le probleme EEG et la physiologie du comportement. EEG Clin. Neurophysiol, 16:130, 1964.

Rua Pompeu Loureiro 83, apt.o 901 - Copacabana - Rio de Janeiro, GB Brasul. 